\title{
IMPERIALISMO, MISSÃO E EXOTISMO: NARRATIVAS DE VIAJANTES DE LÍNGUA ALEMÃ NO BRASIL NAS PRIMEIRAS DÉCADAS DO SÉCULO XX
}

\author{
Imperialism, mission, and exoticism: \\ narratives of German-speaking travelers in Brazil \\ in the first decades of the twentieth century
}

Karen Macknow Lisboa*

\begin{abstract}
RESUMO
O presente texto investiga diferentes tipos de viajantes de língua alemã que estiveram no Brasil nas primeiras três décadas do século XX. Ao analisar aspectos dos relatos de um político colonial (Vallentin), de um representante do partido nacional-socialista alemão (NSDAP) (H. Cossel), de um escritor de viagens (Norbert Jacques) e de dois importantes literatos expressionistas (Kasimir Edschmid e Paul Zech), objetiva-se mostrar a relação desses viajantes com o imperialismo alemão, a ascensão do nazismo e os motivos de suas viagens. Igualmente demonstram-se os pontos de convergência e divergência entre os autores e as principais imagens que constroem sobre o país visitado.

Palavras-chave: literatura de viagem; imperialismo; nazismo; expressionismo.
\end{abstract}

\begin{abstract}
This paper investigates different types of German travelers who visited Brazil from the first three decades of the twentieth century. By analyzing aspects of the reports of a colonial politician (Vallentin), a representative of the German National Socialist Party (NSDAP) (H. Cossel), a travel writer (Norbert Jacques) and two important expressionists writers (Kasimir Edschmid and Paul Zech) the objective is to show the relationship
\end{abstract}

\footnotetext{
"Universidade Federal de São Paulo.
} 
of these travelers with German imperialism, the rise of Nazism and the reasons for their journeys. Also shown are the points of convergence and divergence between the authors and the key images that they build on the visited country.

Keywords: travel literature; imperialism; Nazism; expressionism.

O presente texto tem como foco as narrativas de viajantes da Alemanha ou de regiões de língua alemã que visitaram o Brasil do início do século XX até os anos 30. Minha preocupação é, no exemplo de cinco autores, apresentar ao leitor diferentes perfis de viajantes, aos quais subjazem motivações variadas para a sua viagem ao Brasil. Abordarei nestes escritos algumas especificidades que nos ajudam a compreender esses perfis, no caso, um político colonial, um escritor exotista, dois expressionistas e um membro do partido nacional-socialista alemão (NSDAP). Essa breve discussão pretende contribuir para os estudos sobre a literatura de viagem da primeira metade do século XX a respeito do Brasil, um assunto ainda pouco explorado, sobretudo em relação aos viajantes de cultura germânica e que não eram antropólogos. ${ }^{1}$

Ao longo do século XIX e nas primeiras décadas do XX, o Brasil era considerado um dos países mais importantes para a imigração alemã, sendo superado numericamente só pelos EUA. No período do Império colonial alemão, ${ }^{2}$ muitos viajantes levaram em conta que em termos populacionais as colônias nas Américas eram muito mais representativas do que as possessões alemãs no continente africano e no Pacífico Sul e destarte ocupavam relevante papel nas relações políticas, econômicas e culturais entre os países envolvidos. Vale lembrar que o colonialismo de povoamento por meio da imigração alemã para os territórios africanos e asiáticos não obteve grande sucesso. As razões climáticas e a necessidade de o imigrante

1 O presente texto é uma versão revista e ampliada de LISBOA, Karen Macknow. Aventura, missão e diáspora: os vários motivos de viagens e a necessidade de relatar. In: LANNA, Ana Lúcia Duarte et al. (Org). São Paulo, os estrangeiros e a construção das cidades. São Paulo: Alameda, 2011.p. 443-469. Para aprofundar o assunto, ver LISBOA, K. M. Mundo novo, mesmo mundo. Viajantes de língua alemã no Brasil (1893-1942). São Paulo: Hucitec/FAPESP, 2011.

2 Aqui brevemente resumidas algumas das especificidades do (breve) Império colonial alemão: a) ingresso tardio do Reino alemão na corrida imperialista (em razão da unificação política tardia iniciada em 1871); b) em termos territoriais, o império colonial alemão foi o terceiro maior; c) em termos populacionais, ocupava a quinta posição; d) a Alemanha foi a primeira potência colonial do século XIX que passou pela descolonização (1919). GROSSE, Pascal. Kolonialismus, Eugenik und bürgerliche Gesellschaft in Deutschland, (1850-1918). Frankfurt/M: Campus Verlag, 2000. p. 20. 
ter um capital inicial afugentaram possíveis candidatos à emigração. Mesmo na fase de maior emigração alemã (1880-1893), a maioria (95\%) foi para os EUA, contando um contingente de quase 1,8 milhão de alemães. Em 1913, apuraram-se nas colônias e protetorados alemães os seguintes números: a maior colônia alemã, o Sudoeste Africano Alemão, contava com 14.830 colonos alemães, a África Oriental Alemã com 5.336, Camarões com 1.871, Togo com 368 (ou seja, na África, um total de 22.405). Nas colônias no Pacífico Sul, um total de 1.984 e em Kiautschou, 4.470. ${ }^{3}$ Em termos numéricos, a imigração "alemã" para o Brasil (dependendo do critério empregado, inclui-se nesse grupo imigrantes oriundos de regiões de cultura alemã como, por exemplo, Áustria, Suíça, minorias alemãs na Rússia, Polônia, etc.) foi menor que a italiana e portuguesa. Em decorrência da falta de um controle sistemático da entrada e saída de estrangeiros do país, os números oscilam. Há fontes que indicam que de 1824 a 1940 entraram 235.000 a 280.000 "alemães". Segundo Kellenbenz e Schneider, de 1846 a 1931, foram cerca de 170.000 . Alencastro e Renaux referem-se a 350 mil de 1824 a $1889 .{ }^{4}$ Independentemente dessas oscilações, é notória a diferença em termos populacionais entre essas regiões habitadas por alemães e descendentes e as possessões imperiais alemãs.

Se não podiam ser administradas como protetorados ou possessões coloniais, as "colônias" de imigrantes eram potenciais mercados consumidores de produtos alemães e representantes do reino alemão. No final do século XIX, o economista Robert Jannasch chamou a atenção para a importância das colônias alemãs no sul do Brasil, comparando-as com o que ocorreu nos EUA. Lá os imigrantes da segunda geração teriam se integrado com a população norte-americana, onerando a tarefa dos alemães de outrora terem financiado a educação e a formação de seus "futuros concorrentes". Na opinião do economista, a Alemanha estaria apoiando o desenvolvimento dos Estados Unidos, ao enviar "bons cidadãos" e numerosos trabalhadores diligentes e bem-formados. A única região em que a germanidade

3 GRÜNDER, Horst. Imperialismus und deutscher Kolonialismus in Afrika. In: FÖRSTER, Larissa et al. Namibia-Deutschland - eine geteilte Geschichte. Wolfratshausen: Edition Minerva, 2004. p. 26-43, p. 40.

4 LISBOA, Mundo novo, mesmo mundo... MESSELE-WIESER \& WIESER. Neues Heimatland Brasilien. Begleitband zur Ausstellung. Göttingen: Niedersächsische Staats- und Universitätsbibliothek, 1993. p. 9. ALENCASTRO, Luis Felipe de; RENAUX, Maria Luiza. Caras e modos dos migrantes e imigrantes. In:___ (Org.). História da vida privada no Brasil. Império, a corte e a modernidade nacional. v. 2. São Paulo: Companhia das Letras, 1999. p. 291-335, p. 317. 
(Deutschtum) teria resguardado a sua "consciência patriótica" - e isto apesar dos imigrantes estarem já na quarta geração - era na América Latina subtropical e especialmente no sul do Brasil. Por isto, pleiteia o economista, esta região deveria ser tratada com uma política econômica metódica, no sentido de obter lucros deste mercado cheio de potenciais. ${ }^{5}$

Com o fim da Primeira Guerra Mundial e a perda dos protetorados na África, Ásia e no Pacífico Sul, abala-se o sonho imperialista dos alemães. E as esperanças alimentadas com o "revisionismo colonialista" na década de 1920, retomadas por Hitler, são finalmente enterradas na Segunda Guerra Mundial, depois de 1943 e da derrota em Stalingrado. Contudo, as colônias de imigração continuavam a existir e exercer simbolicamente uma função de Ersatz, de substituição, ou pelo menos de consolo de que havia muitos alemães no além-mar, mesmo em países inimigos. ${ }^{6}$

\section{Viagem, império e política colonial}

O primeiro autor em nossa seleção muito bem exterioriza a intenção econômica e política acima discutida. Vallentin retoma os argumentos de Jannasch, lembrando que nos EUA os alemães se "nacionalizam" e acabam sustentando a potência concorrente. Já no Brasil, abrir-se-ia um mercado consumidor, expandir-se-ia a indústria, encontrar-se-iam novos parceiros comerciais. E, comparado com a África, também prevaleceriam vantagens. Aqui se investiria num país que já possui uma infraestrutura e não como nas colônias africanas, onde é necessário partir do zero. Além disso, as condições naturais favoráveis, como clima e terra, colaborariam para o sucesso de empreendimentos. ${ }^{7}$ Essas conclusões decorrem da própria experiência do autor no Império além-mar. Antes de aportar no Brasil, ocupou o cargo de diretor da colônia alemã nos Camarões e depois permaneceu

5 JANNASCH, Robert apud GRÜNDER, Horst (Org.). ... da unddortein junges Deutschlandgründen. Rassismus und kolonialer Gedanken, Jahrhundert, München: DTV, v. 16, bis 20. p. 220-221, 1999.

6 RINKE, Stefan. Der letzte freie Kontinent. v. 1. Stuttgart: Verlag Hans-Dieter Heinz, 1996. p. 291.

7 VALLENTIN, Wilhelm Julius. In Brasilien. Berlin: Hermnann Paetel, 1909. p. 84-85. 
na Nova Guiné alemã. Não seria demais considerá-lo um típico porta-voz do imperialismo alemão. Esse prussiano nascido em 1862 testemunhou o processo de unificação política e ascensão do Império colonial alemão e, por ter morrido um ano antes da eclosão da Primeira Guerra Mundial, não chegou a ver a sua derrocada. Era economista com doutorado em política e trabalhou como capitão de navios de linhas comerciais. Viajou para África Central, Pacífico Sul e Índia, além de América do Sul. Depois de seu período africano, foi emissário diplomático alemão na Argentina, período em que viajou pelo Brasil e nos países do Prata. Sua passagem pelo Brasil relata em In Brasilien, editado em 1909, ${ }^{8}$ ao lado de outras publicações sobre a Argentina e o Paraguai.

No livro de Vallentin, a narrativa se estrutura conforme as localidades visitadas de um itinerário que inicia em Recife, primeira cidade por ele visitada, e se encerra do outro lado da fronteira brasileira, já na cidade argentina Corrientes. Nessa longa trajetória percorrida via mar, rio e terra, conheceu parte da Bahia, Rio de Janeiro e arredores, Minas Gerais, São Paulo, Vale do Ribeira, Santa Catarina e Rio Grande do Sul. Conforme explica em suas palavras introdutórias, pretende apresentar uma descrição do país e de sua gente que seja acessível ao leitor alemão, sobretudo no que diz respeito às condições econômicas. Dentre os vários temas abordados pelo olhar do viajante, a situação do Deutschtum (germanidade) nas várias cidades e regiões por ele visitadas integra importante tópico nos capítulos. E, de um modo geral, perpassam discussões acerca das potencialidades do Brasil como espaço para a recepção de imigrantes alemães. O capítulo que encerra o livro apresenta algumas reflexões conclusivas, bem como um panorama histórico. Evidencia-se aqui o papel que a Alemanha deveria exercer em relação ao Brasil e em relação às outras nações hegemônicas, dialogando com as disputas de interesses neocoloniais que marcam o período.

Antes de esmiuçar essa questão, pondera quais seriam as contribuições gerais da imigração europeia na América Latina, lançando mão de argumentos raciais, típicos do período. Preocupado com os desdobramentos da mistura racial entre brancos, negros e índios que já ocorria há mais de 400 anos, acredita que um "tipo geral" (allgemeinen Typos) estaria em formação, dotado de uma harmoniosa unidade graças à compensação das 
diferenças por meio do nivelamento das variações étnicas. Como nos EUA se formou o yankee, também na América do Sul ter-se-ia, com o tempo, um "tipo racial próprio" (eigener Rassentypos), que por adaptação e hereditariedade, bem como melhor aproveitamento das condições climáticas e do solo, sintetizará as características de uma "raça dominante" (herrschende Rasse). Por meio de um ideário baseado no darwinismo social e na eugenia, Vallentin depositou a sua esperança na mistura entre os descendentes ibéricos e os novos imigrantes europeus - italianos, franceses e outros, mas sobretudo "germânicos", como anglo-saxões, suíços, alemães, austríacos, escandinavos -, que, vivendo em regiões climaticamente favoráveis e com potencial para serem economicamente exploradas, formariam um "povo" que uniria as "melhores qualidades de caráter" de cada uma dessas nações. $\mathrm{O}$ desenvolvimento do povo brasileiro e do próprio país poderia ser acelerado por meio da introdução dos europeus diligentes, trabalhadores e cheios de energia. Com isso, dar-se-ia início a uma "grande vida cultural", especula $\mathrm{o}$ autor. Em outras palavras, o maior progresso da sociedade brasileira e dos demais países da América Latina dependeria da arianização ou branqueamento de seus habitantes. ${ }^{9}$

Mais adiante, Vallentin faz um apelo, em particular, ao "povo alemão", indagando se este já se deu conta que no Brasil e na América Latina reside uma parte de seu "futuro". ${ }^{10}$ Persuadido de que a imigração de sangue alemão para regiões climaticamente favoráveis - para evitar a degeneração é o melhor "remédio" contra "males políticos e econômicos", pleiteia a vinda de crescente contingente para o Brasil. Pois a concorrência com os demais países vizinhos e, sobretudo, com os EUA somente poderia ser vencida com a presença de mais "sangue germânico" em nossas paragens. Além disso, a questão era superar França e Inglaterra quantitativa e qualitativamente no comércio e na indústria, exigindo que se fincasse atividades econômicas no além-mar. E Vallentin preconiza: “Assim certamente triunfarão também em novos países os dotes naturais do nosso povo, pelos quais já se distinguem: diligência no trabalho, método e exatidão, calma e dura perseverança."11 Vallentin considera o potencial econômico do Brasil muito maior do que o das "próprias colônias" na África e Ásia. Para melhor explorar esse po-

$9 \quad$ Ibidem, p. 248.

$10 \quad$ Ibidem, p. 249.

11 Ibidem, p. 250. 
tencial com o intuito de transformar o "povo alemão em uma verdadeira potência", fazia-se necessária uma "política de estado astuta", lembrando aqui as palavras de Jannasch. Além disso o excedente populacional deveria ser motivado a emigrar para esta região, onde já havia um forte núcleo de "germanidade". Finalmente, para corroborar seus argumentos, Vallentin apresenta ao leitor uma breve tabela mostrando que no Brasil residiriam quase 60 vezes mais alemães e falantes de língua alemã do que em todas as colônias do Império alemão. ${ }^{12}$

\section{Viagem, exotismo e expressionismo}

No contexto do breve Império colonial alemão e da crise do imperialismo, surge na Alemanha uma literatura exotista de viagem. Esta iniciou em torno de 1900 e se mantém até a década de 30, sendo silenciada com a tomada de poder dos nazistas. ${ }^{13}$ A grande novidade é que muitas destas obras emanam de viagens financiadas por editoras ou editores como Georg Müller, Paul Cassirer e Samuel Fischer, que enviam escritores renomados a regiões consideradas exóticas..$^{14}$ Numa primeira fase, ainda anterior à Primeira Guerra Mundial, a Ásia é o espaço predileto para as projeções exotizantes e escapistas de autores de língua alemã. Esse foi o caso dos escritores Hermann Hesse, Max Dauthenday, Hermann Graf Keyserling,

12 Vallentin computa 350.000 alemães e falantes de língua alemã no Brasil em oposição a somente 6.000 espalhados nas colônias africanas e asiáticas. A despeito do possível exagero, vimos acima que a diferença populacional era enorme. Ibidem, p. 252-253.

13 Conforme observa Wolfgang Reif, na Alemanha, como resposta ao desenvolvimento tardio da unificação política, bem como da industrialização e do imperialismo, o exotismo sofre, em relação às outras nações europeias imperialistas, um "atraso" de 20 a 30 anos. REIF, Wolfgang. Exotismus im Reisebericht des frühen XX. Jahrhunderts. In: BRENNER, Peter (Org.). Der Reisebericht. Frankfurt a/M:. Suhrkamp, 1989. p. 434-62, p. 437.

14 Samuel Fischer incentivaria muitos dos "seus" autores a viajarem por regiões extraeuropeias com o intuito de buscar experiências e material inspirador. Para tanto, oferecia ajuda financeira para realizarem suas viagens. Na revista Neue Rundschau, editada pela editora Fischer, procurava-se publicar relatos de viagem que oferecessem uma boa qualidade literária e certa característica autoral. A maioria dos autores que para ela contribuíam não tinha contrato com a editora. Fischer justamente queria que seus escritores, poetas e literatos escrevessem para a revista. Para mais detalhes, ver MENDELSOHN, Peter. $S$. Fischer und sein Verlag. Frankfurt a/M: S. Fischer Verlag, 1970. p. 574 e ss. 
Rudolf Kassner, Alfons Paquet e Elisabeth von Heyking. ${ }^{15}$ Na década de 1920, quando há uma melhora da situação econômica, outros lugares são, por assim dizer, redescobertos, como a África e a América Latina. ${ }^{16}$

$\mathrm{O}$ exotismo do início do século XX revela a fascinação estética e a simpatia pelo estrangeiro enquanto desnuda ao mesmo tempo um processo de desilusão desencadeado pela consciência de se estar vivendo num mundo "descoberto" e europeizado, lembrando o dilema sobre o qual Claude Lévi-Strauss reflete ao referir-se ao fim das "verdadeiras" viagens. Nessa reflexão, escrita vinte anos após a sua estadia no Brasil e, portanto, no contexto da descolonização do imperialismo francês na África e na Ásia, Lévi-Strauss lamenta que ao viajante moderno somente resta correr "atrás dos vestígios de uma realidade desaparecida". Ao mesmo tempo, porém, ele sabe que para o viajante de outrora não existia a noção da diversidade cultural, o que obliterava o conhecimento do "outro". ${ }^{17}$ Compreender a cultura a partir da diversidade e ver o mundo com um olhar crítico sobre os resultados da expansão europeia e do imperialismo eram fruto do pensamento do século XX. Em nem todos viajantes modernos esse dilema - tão bem sintetizado por Lévi-Strauss - é expressado verbalmente. Mas isso não significa que essa ambiguidade não se faça notar nas entrelinhas de seus textos, sobretudo quando se confrontam com a impossibilidade de descobrir o diferente, o que os conduz a uma incessante procura do que acreditam ser o "original", o "primordial", o primitivo da humanidade.

Na literatura exotista moderna, conforme a análise de Wolfgang Reif, o mundo estranho é construído como um oposto à civilização europeia, como uma forma de "contramundo" (Gegenwelt).${ }^{18}$ Nesta contraposição, notam-se momentos de fuga (escapismo da civilização) bem como de crítica (crítica ao imperialismo e à europeização do mundo extraeuropeu) ao lado de uma certa dose de edenização do estrangeiro. Há, portanto, indícios evidentes de que

15 LÜTZLER, Paul Michael. Einleitung. Der postkoloniale Blick. In: (Org.). Der postkoloniale Blick. Frankfurt: Suhrkamp, 1997. p. 14.

16 Reif, op. cit., p. 458.

17 LÉVI-STRAUSS, Claude. Tristes Trópicos. Trad. Jorge Constante Pereira. Lisboa: Edições 70, 1979. p. 32 e 37.

18 Segundo Reif, o exotismo está mais presente na literatura ficcional (Mas Dauthendeys, Willy Seidel, Norbert Jacques, Alfred Döblin, Kasimir Edschmid, Robert Müller) do que nos relatos de viagem. No artigo acima citado, o autor analisa os livros de viagem de Bernhard Kellermann, Ein Spaziergang in Japan (1912), Waldemar Bonsels, Indienfahrt (1916) e Arthur Holitscher, Das unruhige Asien (1926). Reif, op.cit. 
o exotismo pode ser visto como movimento que se opõe à pressão civilizadora do imperialismo e da industrialização; por outro lado, há também uma "afinidade oculta" entre o impulso imperialista de se afirmar mundialmente e a crescente vontade de viajar motivada pelo exotismo. Mas o autor chama a atenção de que estes escritores não se viam como propagandistas do imperialismo alemão e da expansão colonialista, ainda que alguns deles de vez em quando se traiam, abrindo brechas para visões de dominação imperial. Urge diferenciar, ainda conforme Reif, que a propaganda colonialista fica a cargo dos relatos de viagem mais populares ou até científicos de autores nacionalistas (economistas, geógrafos, etnólogos) - tal qual Vallentin - e dos romances populares de temas coloniais (Gustav Frenssen, Hans Grimm), que não estavam preocupados com os movimentos literários do período. ${ }^{19}$

Entre os escritores exotistas, há, por exemplo, o caso de Norbert Jacques, que esteve a primeira vez no Brasil por volta de $1907 .{ }^{20}$ Nesta viagem, realizada, segundo ele, sem dinheiro e destino, recolhe experiências para a redação do opúsculo intitulado Heisses Land, eine Reise nach Brasilien (Terra tórrida, uma viagem ao Brasil). ${ }^{21}$ Jacques, segundo Scholdt, é um "exotista", cujas viagens a regiões no além-mar são substrato para sua produção literária. E nesse aspecto, a primeira viagem ao Brasil valeu como iniciação para a sua obra literária, que em parte foi trazida a lume em artigos na revista Neue Rundschau e tornaram-se um sucesso no gênero da literatura exotista de viagem. Viajar torna-se objetivo de vida, um novo estilo de viver. Em 1912 e 1913, ele realiza uma viagem ao redor do mundo por 480 dias, em grande parte financiada pela editora Fischer e os diários Kölner Zeitung e Frankfurter Zeitung. Na República de Weimar, ele se torna um dos autores mais significativos e criativos no campo dos relatos poéticos de viagem. ${ }^{22}$

19 Ibidem, p. 437-438.

20 Norbert Jacques (1880, Luxemburgo - 1954, Koblenz) escreveu vários romances de aventura e entretenimento, sendo que o Dr. Mabuse, der Spieler, de 1921, foi o de maior sucesso. Tanto este romance quanto a sua continuação serviram de inspiração para alguns filmes, entre eles Das Testament des Dr. Mabuse, com direção de Fritz Lang. Kindlers neues Literatur Lexikon. München: Kindler Verlag, 1990. Um estudo pormenorizado sobre a vida e obra deste autor "esquecido" encontramos na pesquisa de SCHOLDT, Günther. Der Fall Norbert Jacques. Über Rang und Niedergang eines Erzählers. Stuttgart: Akademischer Verlag Hans-Dienter Heinz, 1976.

21 JACQUES, Norbert. Heisses Land, eine Reise nach Brasilien. München: Eichhorn Verlag, 1911(?).

22 Entre 1921 e 1928, Jacques publica seis títulos sobre as viagens para China, Pacífico Sul, Brasil, Sumatra. Sobre os países andinos, edita uma série de artigos. Na década de 30, é publicado o diário de sua viagem pela África. 
Uma segunda expedição às nossas paragens ele realiza por volta de 1924, junto com um grupo de cineastas e cientistas que pretendiam realizar um documentário sobre o Brasil. ${ }^{23}$ No entanto, ele ficaria independente da comitiva e somente os acompanharia na viagem. A ele caberia escrever reportagens sobre o Brasil pós-guerra. O relato segue mais ou menos a ordem de seu deslocamento físico, misturando episódios aventurosos e pitorescos, descrições dos lugares e das pessoas, intercaladas com reflexões sobre o país. Tal como a maioria dos relatos, o dele também inicia no Rio de Janeiro. Após conhecer a capital e os arredores, segue para São Paulo. Depois vai para o sul, com o objetivo de chegar ao rio Uruguai, onde quer visitar as antigas missões jesuíticas e ir à caça de um suposto tesouro, mas não para explorá-lo e sim somente admirá-lo. É nesse episódio que procura realizar o desejo de achar algo típico, original, uma retomada da experiência das "verdadeiras viagens". Neue Brasilienreise (Nova viagem pelo Brasil), publicada em 1925, é uma mistura de diário, capítulos temáticos e descrições de lugares, na qual apresenta uma maior preocupação analítica do país, diferentemente do primeiro opúsculo, acrescida de cenas adequadas ao gosto pelo exotismo. Nesse aspecto, Jacques em muitos momentos consegue construir as imagens dos brasileiros num "contramundo" dos europeus, dos quais querem se libertar econômica e culturalmente.

$\mathrm{O}$ viajante verifica a necessidade do brasileiro de se diferenciar do europeu, de se "proteger" de sua arrogante intromissão em sua vida econômica, cultural e social, embora não se distancie de uma abordagem eurocêntrica. "Os brasileiros são europeus, como nós o somos. No entanto há uma diferença temporal, que nos separa e que tem duas faces." O país é jovem e não possui uma "cultura" sedimentada da qual sua "alma" poderia se nutrir. Isso tudo precisa ser importado da Europa. "O Brasil toma da Europa os instrumentos para o espírito e a alma e, em contrapartida, abastece-a com sua economia." Com essa análise, Jacques reitera que a inserção do Brasil no mundo se dá pela economia, ou seja, baseada em produtos materiais. Por outro lado, ainda segundo Jacques, ao brasileiro faltaria, porém, uma "atitude materialista", aquela que domina os europeus há mais de 70 anos. Os brasileiros resguardariam um Europäertum (Europeidade) anterior à morte de Goethe. É o Europäertum de antes da industrialização, advoga o autor. ${ }^{24}$

23 A produtora do filme era a Deulig (Deutsche Lichtbild-Gesellschaft). JACQUES, Norbert. Mit Lust gelebt. Edição crítica. St. Ingebert: Röhring UniversitätsVerlag, 2004. p. 315.

24 JACQUES, Norbert. Neue Brasilienreise. München: Drei Masken Verlag, 1925. p. 24. 
O autor apresenta exemplos para mostrar esta "atitude antimaterialista". Satisfeito com o desempenho de um empregado, o patrão aumenta-lhe o salário, tendo como consequência que o empregado falta dois dias no trabalho, o que antes nunca fizera. O patrão pede-lhe uma explicação: agora não precisaria labutar mais tanto. Com essa quase anedota, o autor, distanciado de uma avaliação moral acerca do caráter supostamente indolente e preguiçoso do brasileiro, quer provar a falta de uma mentalidade capitalista na sociedade. "Assim, se explica o fato de que o Brasil fornece a sua rica economia aos EUA e Europa, para manter para si somente o campo da política e de sua vida particular". Daí a origem dos conflitos entre europeus e brasileiros. Os brasileiros não estariam preparados para suportar o poder dos comerciantes europeus, que estão se impondo há quase um século. Em suma, o autor enxerga nisso tudo uma atitude louvável no contexto das lutas pela dominação de mercados: "O brasileiro resguardou algo mais nobre do que o nosso espírito e a nossa visão de mundo", elogia o autor. ${ }^{25}$

Semelhante situação Jacques teria percebido na China, onde atestou uma relação tensa entre os chineses e os europeus. "Será a desconfiança que têm dos europeus que os faz se fechar diante deles", pergunta-se. "Pois aparecemos forçosamente como hipócritas devido à nossa moralidade religiosa e de Estado, bem como às manifestações de nosso ser. Jamais em viagem pelo Brasil observei que os europeus fossem de fato aceitos em famílias brasileiras." Nas observações de Jacques, há nítidas dimensões de uma crítica ao imperialismo, bem como às atitudes arrogantes dos europeus. No entanto, prevalece a ambivalência que ora se revela em puras observações eurocêntricas e em repetições de preconceitos já tão naturalizados. Se em certos momentos elogia o antimaterialismo dos brasileiros, em outros retoma argumentos raciais, alegando ser ele herança dos negros e índios. E nesse sentido, provoca os brios patrióticos: em vez de "ordem e progresso", o lema da bandeira nacional deveria ser "amanhã e paciência". ${ }^{26}$

Dentre os literatos, há ainda autores representantes das vanguardas artísticas, em particular do expressionismo, importante movimento cultural que nasceu na década de 1900 na Alemanha, ou seja, coetâneo à literatura exotista. Nas artes plásticas, o expressionismo foi liderado pelos grupos de vanguarda como o Brücke, fundado 1905 em Dresdem, e o Blauer Reiter, 
uma dissidência de um grupo de Munique e que em pouco tempo se internacionalizou. Na literatura, o epicentro do movimento encontrava-se Berlim e se alastrou durante a primeira Guerra Mundial Mundial. ${ }^{27}$ Foi nesse período que Kasimir Edschmid, um dos viajantes que passa pelo Brasil no final dos anos 20, lançou o único manifesto em alemão sobre o expressionismo. Em sua concepção, o movimento não deveria ser "alemão nem francês", mas sim "supranacional [...], uma coisa da humanidade". ${ }^{28}$ Em confronto com as premissas do naturalismo e do positivismo, Edschmid expõe em 1918 um dos alicerces do expressionismo: a realidade como construção ativa. ${ }^{29}$ A preocupação do escritor ou artista não era mais encadear os fatos, tais como "fábricas, casas, doenças, prostitutas, gritaria e fome" por meio de uma lógica de causalidades. O que existia com o expressionismo era a "visão" disso tudo. "Os fatos têm significado somente até o ponto em que a mão do artista o atravessa para agarrar o que se encontra além deles". ${ }^{30}$

Edschmid contribuiu para o movimento expressionista com o manifesto e os seus contos, em que se aproximou do "expressionismo messiânico", apresentando traços triviais e até dissimuladamente fascistoides. $\mathrm{Na}$ década de 1930, tornara-se um escritor de viagem de bastante sucesso, espalhando o "gosto pela aventura", em que se nota uma trivialidade em suas descrições, distanciando-se da radicalidade do movimento do qual participou outrora. ${ }^{31}$

O livro sobre a viagem pela América do Sul, datada do final da década de 1920, chama a atenção pelo seu título por conter uma antonímia recorrente nas obras de estrangeiros sobre a América ibérica, no caso inspirada em Balzac: Esplendor e miséria na América do Sul, romance de uma parte da terra, publicado em $1932 .{ }^{32}$ Trata-se da narrativa da viagem de um personagem ficcional, autobiográfico, chamado Göhrs, alter-ego

\section{$2-5$.}

27 ANZ, Thomas ANZ. Literatur des Expressionismus. Stuttgart, Weimar: Metzler, 2002, p.

28 Edschmid apud TELES, Gilberto Mendonça. Expressionismo. In: Vanguarda europeia e modernismo brasileiro. Petrópolis: Vozes; Brasília: INL, 1976. p. 106.

29 Cf. Anz, op. cit., p. 7.

30 Edschmid apud Teles, idem.

31 VIETA, Silvio; KEMPER, Hans-Georg. Expressionismus. München: Wilhelm Fink Verlag, 1997. p. 215; GLASER, H.; LEHMANN, J.; LUBOS, A. Wege der deutschen Literatur, eine geschichtliche Darstellung. Frankfurt/M: Ullstein, 1975. p. 360.

32 EDSCHMID, Kasimir. Glanz und Elend Süd-Amerikas, Roman eines Erdteils. Hamburg: Paul Zsolnay Verlag, 1950. (Reedição de 1932 com fotos de Erna Pinner). 
de Edschmid. Na apresentação, é revelado ao leitor que Göhrs não estaria viajando para "descobrir" alguma coisa. Ele seria um escritor que odiava os termos "expedição" ou globe-trotter. O primeiro lhe parecia pretensioso e o segundo, estúpido. Também não estaria viajando como um britânico, que, receoso, investiga todos os aspectos, pensando na manutenção do Império britânico. Tampouco faria como um francês, que viaja com Paris em seu coração, enxergando o mundo como uma grande incógnita. Em contrapartida, interessava-se por coisas que, em geral, não atraíam os alemães. A sua pergunta girava em torno do papel que as diferentes raças exerceriam no palco mundial e por que havia tantas animosidades. Preocupava-se com as diferenças sociais entre a Europa e a América do Sul e com os conceitos que definem o que se entenderia por progresso. Na epígrafe, já anuncia a sua opinião de que o continente estava condenado a regimes ditatoriais. Essa seria uma de suas convicções depois de ter visitado o Caribe, Panamá, Venezuela, Colômbia, Equador, Peru, Bolívia, Chile, Argentina e, por fim, o Brasil das cidades portuárias (Rio, Santos, Salvador, Recife).

Apesar deste avant-propos sugerir uma autocrítica do viajante europeu "eurocêntrico" e apresentar duas questões fundamentais para fazer a crítica ao "imperialismo", o seu relato de viagem tematiza as questões de forma bastante simplificada e trivializada. O livro, que para o autor deveria ser lido como um romance, parece servir mais de entretenimento associado a certa dose didática. A questão mais polêmica, quando trata do Brasil, é o enaltecimento da nossa paz racial, apontando para uma apropriação do discurso de uma certa elite brasileira. Edschmid atribui ao Brasil e à sua solução racial um lugar de destaque no contexto mundial, contrastando-o com o que ele teria visto antes na África. Para a ditadura de Hitler, o romance de viagem de Edschmid foi avaliado como provocador e proibido por conter ideias simpáticas à miscigenação racial e por ser um entusiasta da etnia negra. ${ }^{33}$

Para provar a nossa paz racial, o autor descreve situações que atravessam vários segmentos sociais. Uma recepção da alta society num hotel de luxo; uma "excursão de proletários" no bonde; um passeio por um bairro pobre; uma visita ao Teatro Recreio. A partir de uma estrutura dialógica em que quase sempre transcreve a opinião de um "mediador", deu voz aos 
personagens locais, subvertendo uma possível arrogância do viajante europeu. O quanto há de ficcional em sua narrativa fica em aberto, pois o que prevalece é a verossimilhança dos quadros de vida apresentados ao leitor.

Vejamos a cena de uma recepção no "Hotel Copacabana", deve ser o Copacabana Palace, na época o hotel mais luxuoso do Rio. Entre a "alta sociedade" que lá se encontrava - ministros, diplomatas, industriais, deputados, magnatas do café - a grande parte das mulheres, todas elas muito atraentes, tinha sangue indígena e, sobretudo, africano, avalia o autor. Neste meio chamava atenção um negro, de estatura alta, maior que os demais. Ao descrevê-lo, Edschmid revela seu espanto, deixando entrever resquícios de seus preconceitos raciais: "Ele tinha um corpo virtuoso e olhos inteligentes, como jamais vira num negro" (grifo nosso). Todos os convidados cumprimentavam-no. $\mathrm{O}$ viajante afirma que nunca teria presenciado algo semelhante. Na África do Sul, testemunhou como reis negros e até um nobre como Ghandi teriam sido expulsos do trem e do hotel, por não serem brancos. Num navio em que viajou, viu como ao representante dos trabalhadores africanos no Völkerbund (Liga dos Povos) foi proibido frequentar o salão e como passageiros norte-americanos queriam abandonar uma embarcação, depois que um professor negro teria entrado no fumoir. Igualmente, conheceu cidades africanas onde os negros não podiam andar na calçada. Devido a essas experiências, o protagonista ficou ainda mais surpreendido ao notar que as pessoas reunidas no evento pertenciam à alta society do Rio. Conclui que em nenhum lugar do mundo a questão racial foi "descartada" de forma tão soberana, certeira e com humor, tornando-a uma questão de segunda importância para a vida. ${ }^{34}$

A paz racial agia como uma "vantagem colossal". Pelo mundo afora, sobretudo na África e Ásia, vislumbram-se guerras raciais, menos no Brasil. Por outro lado, o autor não deixou de notar que havia segregação por razões econômicas: transmitindo a opinião de um brasileiro, ensinou: "Aqui de fato é o único país do mundo onde a cor do pescoço é insignifi-

34 Edschmid, op. cit., p. 418-421. Edschmid de fato viajou pelo sudoeste, sul e sudeste da África antes de conhecer o Brasil. Deixou registradas suas experiências no livro Afrika nackt und angezogen. Na nota introdutória, externou o propósito de sua viagem e da escrita do livro que visava contribuir para a questão acerca de qual das etnias, a branca ou a negra, dominará na África. Em algum momento, o destino iria decidir essa disputa. EDSCHMID, K. Afrika nackt und angezogen. Land der ursprünglichen vitalen Rasse. Frankfurt a/M.: Societäts Verlag, 1934. 
cante; o que importa é se em torno dele há um colarinho". ${ }^{35}$ Para Edschmid, a forma como a questão racial era praticada emprestava ao Brasil um papel único e especial no contexto mundial. As comparações serviam de prova para essa particularidade.

Outro aspecto marcante em suas descrições era o seu fascínio pelas negras de "sangue puro". Aqui se retoma a tensão entre o exotismo e o olhar imperialista europeu. Para o autor, eram as mulheres de classe baixa que tinham de fato "raça" e não as morenas claras ou escuras da alta sociedade, por mais belas que fossem. Essa predileção confessa ao atravessar um bairro pobre nas imediações do Jóquei Clube no Rio. As exclamações não cessam:

Que bairro incrível! Que mestiços! Que moradias! Que caras! Que gentalha mais arrogante. Entre as moças, havia criaturas lindas e atraentes, que dependendo da porcentagem de sangue branco, tinham corpos completamente diferentes, articulações completamente diferentes, olhos e ancas diferentes. Não somente a cor era diferente, o que é secundário, mas as cabeças e os corpos eram diferentes. [...] Muitas dessas moças mestiças ainda guardavam o encanto do movimento das puras africanas - não há ninguém que caminhe de maneira mais bela que uma negra no interior da África - e tinham corpos perfeitos, belos e adequados ao gosto europeu. [...] As mulheres de cor da sociedade não tinham tanta "raça". ${ }^{36}$

Edschmid mostra o seu encanto pelas negras, forjando uma imagem exotizada, em que insiste em realçar o "diferente", como a citação acima revela. $\mathrm{O}$ belo e o vital encontram-se nas classes mais inferiores, as quais Edschmid considera mais "genuínas", menos europeizadas e para ele (e leitores) menos acessíveis. Retoma-se aqui o desejo da viagem ao "original", como uma das características da literatura do exotismo misturadas com algumas dimensões do expressionismo. O gosto pelos "pobres", pelo o que não representava os valores burgueses criados na Europa ocidental, resguardaria ainda um tom de recusa ao convencional. Por outro lado, Edschmid estetiza a "raça negra" seguindo os ditames do gosto europeu, conforme ressalva em suas palavras, e ao mesmo tempo valoriza a ideia da pureza racial.

36 Edschmid, op. cit., p. 450-451. 
Se Edschmid, ao passar pelo Brasil, já teria se afastado do expressionismo, Paul Zech, outro importante escritor do movimento, o leva em seu relato de viagem adiante. ${ }^{37}$ Nele é possível perscrutar a forte crítica à civilização e o mal-estar com o mundo da tecnologia e do capitalismo. Seu relato, em parte ficcional, apresenta a estética do grotesco, dos sentimentos extrapolados, do medo e da angústia, tudo isso narrado em uma linguagem direta, em parte telegráfica, quando não bruta.

Paul Zech emigra em agosto de 1933 da Alemanha nazista. Naquela época, ele já era um autor esquecido. Seus trabalhos em prosa e poesia de cunho pacifista e de crítica social ${ }^{38}$, suas traduções do francês, sua atuação de crítico literário e dramaturgo, bem como editor da revista Das neue Pathos, faziam parte do passado. Pois, na década de 1920, o autor protagonizou escândalos de plágios e provavelmente até roubo de obras raras no tempo em que trabalhou na Stadtbibliothek (biblioteca da cidade) de Berlim. Problemas com a justiça desacreditaram a idoneidade do autor, o que contribuiu para a sua decadência no meio literário, pondo em questão a sua validade como escritor e publicista. ${ }^{39}$

Na década de 1930, poucos se lembravam de suas polêmicas marcadas pela forte crítica ao capitalismo selvagem ou se referiam à sua prosa pacifista, e também já estava esquecida a sua atuação como chefe do departamento de propaganda dos socialistas na Revolução de 1918. Quando em 1933 os nazistas impõem a Gleichschaltung ideológica e política que atinge o meio cultural, desembocando na lista dos autores e obras proscritos, o nome de Zech nela não se encontra. ${ }^{40} \mathrm{~A}$ fuga repentina de Zech em agosto de 1933 dificilmente se explica por razões de perseguição ideológica ou

37 ZECH, Paul. Südamerika: Alles und Nichts. Eine nicht ganz einfache Reise ins Blaue hinein. 2 v. Mimeo. Stiftung Akademie der Künste. Berlin: Arquivo Paul Zech, 1935/1942.

38 No contexto da Primeira Mundial, passou de entusiasta para crítico do conflito, depois de ter participado como oficial lutando no front. Em 1919, Zech publica o seu libelo pacifista Das Grab der Welt. A essa altura, o autor já havia alcançado reconhecimento e boa aceitação nos meios literários com a publicação da antologia de contos Der schwarze Baal, uma crítica social às péssimas condições de trabalho nas minas de carvão, onde o próprio autor chegara a trabalhar em sua juventude.

39 KASTIES, Bert. "Leben bei einem Ende und vor einem Anfang". Paul Zech - Annäherungen an einen Verwandlungskünstler". In: ZECH, Paul. Ausgewählte Werke. v. 1. Bert Kasties \& Dieter Breuer (Org.). Aachen: Shaker Verlag, 2001. p. 20-28. Agradeço a Bert Kasties de ter me cedido os direitos de publicar passagens da obra inédita de Paul Zech.

40 A cassação de partidos, órgãos, sociedades, etc. pelos nazistas deu-se logo após a ascensão de Hitler ao poder. Em março de 1933, com a criação da Reichskulturkammer (Ministério da Cultura), sob a chefia de Goebbels, a Gleichschaltung atingiu os meios culturais. 
étnicas. Zech não era judeu, não tinha antepassados semitas e a sua simpatia pela social-democracia não parece ter sido suficiente para colocá-lo no banco dos condenados à morte ou ao exílio. A breve detenção de Zech pela polícia de Berlim em março de 1933 não deve ter sido por motivos ideológicos, mas provavelmente em decorrência de seu envolvimento com o roubo de obras raras. $\mathrm{E}$ o fato de as autoridades nazistas não terem demonstrado algum interesse em perseguir ou proibir a sua obra levanta dúvidas de que Zech tenha deixado a Alemanha por razões políticas, versão que o próprio autor, porém, propagava. Igualmente, até agora não há nada que prove a sua Ausbürgerung (expatriamento), à qual Zech continuamente se referia. ${ }^{41}$

No "exílio", Zech soube explorar as vicissitudes históricas a seu favor, construindo a autoimagem de um autor perseguido e forçado pelo regime nazista a deixar o país ${ }^{42}$ - o que não corresponde exatamente aos fatos e que precisa ser visto com cuidado, sem, no entanto, menosprezar o perigo que muito provavelmente teria corrido se tivesse continuado na Alemanha. Em suma, o seu processo de exílio apresenta peculiaridades, tornando o seu caso extremamente ambivalente.

Supõe-se que antes de chegar ao seu destino, na Argentina, onde viveu até sua morte, em 1946, tenha passado por Praga, Paris, Gênova e Nápoles. O relato de viagem inicia com a saída da Europa e a travessia do Atlântico, antecipado por um capítulo introdutório no qual reflete sobre sua condição de "exílio". ${ }^{43}$ No continente americano, Recife foi a sua primeira estação em $1935 .{ }^{44}$ Seguiu depois com o navio para Salvador, Rio de Janeiro, Santos, Montevidéu e Buenos Aires. Os capítulos do relato revelam outros

41 Cf. Kasties, op. cit.

42 O processo do exílio de Zech é amplamente tratado na pesquisa de Spitta e outros autores, como Alfredo Schwarcz, mas sempre baseado na premissa de Zech ter sido perseguido ativamente pelo regime nazista e de ter sido uma vítima do estado ditatorial, assumindo, portanto, a versão do próprio autor. Schwarcz refere-se a uma emigração forçada, não desejada, produto de um ambiente hostil que o expulsa. Cf. SPITTA, Arnold. Paul Zech im südamerikanischem Exil, 1933-1946. Berlin: Colloquium Verlag, 1978, e SCHWARCZ, Alfredo. Consideraciones psicológicas en torno a la migración. El caso Paul Zech. In: LANGBEHN, Rohland de, Regula: Paul Zech y las condiciones del exilio en la Argentina 1933-1946. Buenos Aires: Fac. de Fil. y Letras, UBA, 1999. p. 65-68. Vale mencionar que na pesquisa de Spitta, que versa sobre a "obra de exílio" de Zech, o relato de viagem é tratado marginalmente.

43 Zech, op.cit., v. 1.

44 Há dúvidas quanto à data. Spitta afirma que Zech chegou em dezembro de 1933. Portanto, a passagem pelas cidades portuárias brasileiras mencionadas no relato em 1935 teria ocorrido em 1933. Cf. Spitta, op.cit. p. 64. Para mais detalhes, ver LISBOA, K. M. De passagem pelo Brasil: Paul Zech a caminho de seu exílio. In: THORAU, Henry (Org.). Heimat in der Fremde. Berlin: edition tranvía, Verlag Walter Frey, 2007. p. 393-396. 
lugares que teria visitado: Paraguai, Bolívia, Peru, Chile e Equador, dentre os quais "Uma pequena viagem à Amazônia" e "Uma segunda viagem à floresta virgem no Brasil". No entanto, também aqui não há provas de que tenha realizado estas expedições. Estes capítulos devem ser ficcionais e muito provavelmente se baseiam em relatos de outros viajantes, embora Zech tenha afirmado, por exemplo, em uma carta a Zweig, que teria vivido por três meses em fazendas e estâncias no Uruguai e no Brasil, onde teria experimentado o "ermo absoluto". ${ }^{45} \mathrm{O}$ relato também apresenta subcapítulos que narram episódios fechados, como pequenos contos. Zech não conseguiu publicar o relato de viagem, deveras longo. Chegou a editar alguns capítulos isolados em periódicos. A sua situação em Buenos Aires era complicada. Faltava-lhe dinheiro e enfrentava grandes dificuldades em encontrar editores para suas obras. ${ }^{46}$

O Brasil real e imaginário de Zech emana de um olhar crítico sobre as condições sociais que nas breves estadas conseguiu captar. A esse aspecto de crítica social somam-se abordagens exotizantes e erotizadas da sociedade e da natureza, que têm como pano de fundo as convicções vitalistas às quais o autor se filiava. ${ }^{47}$ Grosso modo, sua percepção de Brasil, que se estenderá para as demais regiões da América Latina, deixa transluzir uma constante em suas descrições: o que caracteriza a sociedade brasileira são os extremos contrastes entre pobres e ricos, entre dominadores e dominados. Zech divide a sociedade entre a classe dos ex-colonizadores europeus miscigenados detentora do poder - e esta associada à Igreja - por um lado e, por outro, a massa dos explorados formada por descendentes afro-indígenas e imigrantes mais recentes de classe baixa.

A partir dessa característica básica da sociedade brasileira, é possível perscrutar três temas recorrentes em sua obra: a decadência moral e

p. 104.

45 Carta de Paul Zech a Stefan Zweig, Buenos Aires, 29 de dezembro de 1936. Daviau, 1986,

46 Cf. Spitta, op.cit.

47 O vitalismo ou "culto à vida" foi uma tendência filosófica em voga no final do século XIX e início do XX, cujos representantes mais relevantes foram F. Nietzsche, Henri Bergson e Georg Simmel. Nele evidencia-se a glorificação da vida, desprendida da ideia de sentido ou de conteúdo imanente. O culto à vida vai além do indivíduo, procurando abarcar a vida em geral, em sua totalidade, como instância supraindividual, como uma corrente eterna que transpassa cada indivíduo. O vitalismo se compreende como um pensamento antirracionalista, que foi incorporado pelo expressionismo. Na literatura ficcional alemã, foram vários autores expressionistas que reproduziram as ideias vitalistas, entre eles Else Lasker-Schüler e Richard Dehmel, autores que exerceram forte influência sobre a obra de Zech. Sobretudo Lasker-Schüler. Para mais detalhes, ver Spitta, op. cit., p. 78-80. 
em parte física da classe dominante, cujos indivíduos são cínicos, egoístas, superficiais, materialistas e insensíveis à dura realidade social do país. Formam eles um pequeno segmento da sociedade que concentra os bens e as rendas da economia. Nas palavras de Zech, suas preocupações giram em torno da cotação do café (principal eixo de sustentação da economia brasileira na década de 1930), suas férias em Paris, Londres e em todos os lugares onde se vive bem. Apesar da crise mundial, essa classe continua rica e incapaz de renunciar a qualquer coisa imprescindível para que um "grande proprietário de terra brasileiro se apresente como um homem culto: o Derby, a ópera, o cassino, o marchand e as mulheres da Europa central, brancas e mais frias". 48

Em contraste com essa elite, que vive num exagerado esplendor, ao leitor é apresentado o segundo grande tema: a miséria social. Já na sua primeira estação no Brasil, no Recife, depara-se com as favelas que, a seu ver, em nada contribuem para o quadro pitoresco da urbe, tal qual autores como Zweig ${ }^{49}$ lograram fazer em seus panegíricos sobre a terra alheia. Em Zech, a favela é suja e paupérrima:

[...] onde as famílias negras moram em latas de alumínio [...], onde a mais anciã estende a roupa do corpo na cerca viva, em frente ao seu "cômodo", onde não se avista nem porta nem janela. Tão rápido como o sol escaldante seca a roupa, urubus tomam conta do lixo, o qual simplesmente é despejado ou jogado à rua. Falar em rua é exagero, [...] são picadas [...]. No campo, atrás dos barracos [...], borboletas dançam. A única menção a flores nesse cinza e abominável monte de lixo aplanado. ${ }^{50}$

Em Salvador sugere ao visitante recém-chegado que deva começar a visita pela cidade-baixa, para não ter uma imagem equivocada do lugar. Pois é lá que moram os pobres e os negros ainda bem retintos, ensina Zech, em barracos miseráveis de caixas de madeira e bambu, com suas famílias de 10 a 15 filhos, "todos com barrigas inchadas e perninhas finas e tortas,

48 Zech,op.cit., v. I, p. 75-76.

49 Aqui me refiro ao best-seller de Stefan Zweig, Brasilien, ein Land der Zukunft (Brasil, um país do futuro), publicado em 1941. Sobre a visão idealizada da favela na obra de Zweig, ver Lisboa, Mundo novo, mesmo mundo, p. 217-219.

50 Zech, op.cit., v. I, p. 60. 
cabeças grandes e olhos arregalados".${ }^{51}$ A pobreza que Zech teria visto na cidade-baixa e no cais era de uma tal "palpabilidade" ("ist so handgreiflich"), que ao transeunte, que "ainda sente a assombração da Europa em seus ossos e cabeça e que certamente já viu em sua vida algumas formas de assustadora pobreza, o peito lhe sufoca e o coração bate em descompasso". ${ }^{52}$ Aqui Zech toca uma outra questão recorrente em sua obra de exílio: o europeu ainda não aculturado, não acostumado com a realidade social latino-americana, apresenta uma sensibilidade humanista, uma empatia pelos outros, que com o tempo perderá, igualando-se moral e socialmente à decaída elite local. ${ }^{53}$

O terceiro tema recorrente no relato de viagem tange à questão racial. Zech, tal qual muitos outros viajantes, espanta-se nos primeiros momentos no solo brasileiro com o "colorido" da nossa sociedade: assim que aporta no Recife se diz perplexo com os negros ("verblüffendste Eindruck sind die Neger"). Confessa-se ignorante em relação à América do Sul, por não saber que lá viviam tantos negros e descendentes de negros. ${ }^{54}$ Mas, ao contrário de muitos estrangeiros, reconhece seus preconceitos e a necessidade de rever tudo aquilo que o havia formado na Europa. "Aqui urgia um reaprendizado minucioso, sobretudo para nós europeus que, apesar de tudo, queríamos continuar a imaginar um mundo europeu". ${ }^{55}$ Também diferentemente de outros europeus (e brasileiros), Zech não está preocupado em provar alguma teoria racial ou inferioridade nata de alguma "raça"56. Por um lado registra estranheza em relação aos afrodescendentes e por outro mostra-se consternado com sua pobreza e procura compreendê-la historicamente, associando-a ao fardo da escravidão e da ininterrupta exploração por parte da elite local e dos europeus. No Recife, andando de bonde, Zech, no meio de uma maioria de passageiros não brancos, explica:

51 Zech, op.cit., v. I, p. 73.

52 Idem.

53 A esse respeito ver também a análise de Spitta sobre o "Verhiesigte" na obra de exílio de Zech. Spitta, op. cit., p. 112-115.

54 Zech, op. cit., v. I, p. 56-57.

55 Ibidem, v. I, p. 98.

56 Nunca é demais lembrar que na década de 1930 o racismo cientificista permanece moeda corrente entre numerosos autores, além de servir como argumento para políticas imperialistas e, na pior de suas versões, genocidas. No caso da literatura de viagem de língua alemã sobre o Brasil desse período há vários exemplos de autores abertamente "racistas": H. Ullmann, A. Funke, H. Cossel, E. Krieger. Para mais detalhes ver Lisboa, Mundo novo, mesmo mundo. 
[...] eles tiveram que se curvar por muito tempo; hoje já são senhores, com salários miseráveis, mas livres. Pelos menos livres em seus movimentos, na escolha de seus patrões e das opiniões de seus jornais, de seus líderes políticos. Mesmo assim, é gente estranha, quando querem dar uma de supereuropeu com suas quinquilharias japonesas que compram nos bazares. Quando as rubras meias de seda mostram furos do tamanho de um punho $[\ldots]^{57}$

As menções de Zech quanto às liberdades desfrutadas pelos descendentes africanos podem ser compreendidas na particularidade do ano de 1933, quando o "governo provisório" estava em marcha de se constitucionalizar pautado numa carta magna - inspirada na constituição da República de Weimar - em que a democracia e os direitos dos cidadãos estariam garantidos, ${ }^{58}$ o que infelizmente será desmentido em 1937, com o golpe de estado conduzido pelo próprio Vargas com apoio de certos grupos políticos e do exército. Zech talvez até estivesse exagerando com as tais liberdades dos pobres, sobretudo quanto à escolha dos políticos, mas ele ao menos não idealiza as nossas relações raciais. Não como Edschmid o faz, indicando a apropriação da ideia da "democracia racial" - o termo é posterior ao conceito ${ }^{59}$ - assunto tão caro não somente aos europeus que nos visitam no período, mas também à elite pensante brasileira, que estava em vias de construir uma identidade positiva a respeito de sua particularidade em termos de formação étnica. Em sua breve passagem pelo Brasil, Zech verifica um racismo dos negros em relação aos brancos, que se explica por razões históricas. E são estas razões que justamente emprestam à camada negra e pobre um forte potencial revolucionário.

57 Zech, op. cit., v. I, p. 65-66.

58 No ano de 1933, o "governo provisório" de Vargas decidiu constitucionalizar o país, realizando em maio eleições para a Assembleia Constituinte, que foi aprovada em 1934. Um dos aspectos relevantes da Constituição foi a legislação trabalhista, mais favorável aos direitos do trabalhador de ambos os sexos. Além disso, estabeleceu-se o ensino primário gratuito e a frequência obrigatória das crianças nas escolas.

59 Entre os sociólogos e intelectuais brasileiros, o termo "democracia racial" aparece a partir de 1940. Segundo A. Guimarães, o termo foi cunhado por Roger Bastide para uma livre interpretação das ideias de Gilberto Freyre acerca da democracia brasileira. Freyre reporta-se inicialmente a uma democracia étnica e social. Somente em 1962, Freyre faz uso do termo "democracia racial", que já foi empregado na década de 1950 por Abdias do Nascimento e Charles Wagley na introdução ao primeiro volume dos célebres estudos sobre as relações raciais no Brasil, patrocinados pela UNESCO. Para mais detalhes, ver GHIMARÃES, Antonio Sérgio Alfredo. Classes, raças e democracia. São Paulo: Editora 34, 2002. p. 137-168. 
Finalmente, Zech não hesita em vislumbrar no Brasil uma "revolução que virá de baixo", portanto, dos excluídos, formados em sua maioria por descendentes africanos. Essa revolução não tem como base uma organização política ou alguma ideologia partidária de esquerda. Por trás dela estão os negros que foram traídos pela abolição e desde então adquiriram um outro conceito de liberdade, diferente daquele do grande proprietário de terra, que a interpreta somente para os interesses próprios. E os brancos empobrecidos poderão se unir a estes negros e mestiços, profetiza o autor. ${ }^{60}$

\section{Viagem, missão e nazismo}

Por fim, um exemplo de um viajante "colonialista" bastante sui generis. No mesmo ano em que Paul Zech foge da Alemanha, o alemão H. Cossel, nazista, que vivia em São Paulo, viaja para a sua terra natal. Sua incumbência é obter instruções políticas ao visar à organização do partido nazista alemão no Brasil. Em 1934 ele desembarcaria novamente em Santos. ${ }^{61}$ Sua atividade no Brasil, em particular em São Paulo, onde se encontrava a sede do partido, cobriu o período de 1931 a $1942 .{ }^{62}$ Nesse ínterim, Cossel, chefe do partido regional, realizou viagens para o sul do país. Seu motivo maior era conhecer as colônias teuto-brasileiras, avaliar o quanto preservavam a germanidade ("Deutschtum") e, de quebra, angariar novos membros. Em seu breve artigo intitulado "Eine Reisedurch das Deutschtum in Brasilien", publicado em 1935 pelo Verband Deutscher Vereine im Ausland (Liga de Associações alemãs no exterior), narra as passagens por Rio de

60 Zech, op. cit., v. II, p. 444-445.

61 Sua atividade no Brasil, em particular em São Paulo, onde se encontrava a sede do partido, cobriu o período de 1931 a 1942. Cossel também foi adido cultural no Consulado da Alemanha em São Paulo. Ao que tudo indica, voltou no início de 1943 para a Alemanha, junto com outros representantes diplomáticos e membros do Partido Nazista. DIETRICH, Ana Maria. Caça às suásticas. São Paulo: Humanitas, Imprensa Oficial do Estado de São Paulo, FAPESP, 2007. p. 158-163.

62 O primeiro grupo regional do NSDAP no Brasil foi fundado em 1928, em Timbó, perto de Blumenau. Em 1931, ele foi reconhecido oficialmente na Alemanha, como foi o caso em outros países da América Latina. Ulteriores grupos surgiram no Rio de Janeiro, São Paulo, Porto Alegre, Blumenau, Joinville, Ijuí. Apesar do número relativamente baixo de filiados, comparando com a população de cidadãos alemães e descendentes no Brasil, eles eram bastante ativos e dinâmicos. Cf. Rinke, Der letzte freie Kontinent..., v. I, p. 409. 
Janeiro, São Paulo, Santos, Paraná, Santa Catarina e Rio Grande do Sul, com o olhar focado nas colônias alemãs, tanto na área rural como nos centros urbanos. Em suas descrições, o nazista procura mostrar as peculiaridades da vida dos alemães no Brasil, sua cultura, suas instituições e edificações, bem como as atividades econômicas, as dificuldades dos imigrantes e a relação com a sociedade receptora. Em vários lugares, afirma que a cultura, a língua e a identidade com a pátria original se mantiveram (na cidade de São Paulo, por exemplo, podia-se tranquilamente viver sem falar o português), o que, no entanto, não era garantia de que o Deutschtum não estivesse ameaçado de extinção. ${ }^{63}$ Preocupado com o "híbrido" teuto-brasileiro, lança mão do racismo biológico para demonstrar que o sangue do povo germânico podia e deveria ser preservado nos rincões extraeuropeus, vislumbrando um forte elo de conexão entre os alemães no III Reich e os "alemães no estrangeiro"64.

Blumenau representaria o centro do Deutschtum no Brasil. Tanto na cidade como na região rural, mal se ouvia uma palavra em português. Mesmo os poucos negros falavam alemão e se sentiam "teutônicos". Os habitantes apresentavam com "orgulho" os seus filhos já na quinta geração, cuja "pureza racial (rassisch) e de ascendência (völkisch) preservou-se." A sua pátria (Heimat), não obstante, era o Brasil. Esta geração já não conhecia mais a Alemanha e para ela as palmeiras não eram mais um fator de estranhamento como foram para os seus ascendentes, explica o autor. Ainda assim, persistiria um elo entre as novas gerações e a velha pátria: "Um laço formado pelo mesmo sangue e a mesma tradição, a mesma cultura e a mesma mentalidade (Geisteshaltung). E uma vez reconhecido este laço, será fácil retomar o caminho para os nossos irmãos no longínquo Brasil" ${ }^{65}$ Baseado nessa conexão sanguinea e atávica, o autor quer resgatar os habitantes de origem alemã que se afastaram da cultura germânica. Esse era o caso de Curitiba e São Leopoldo - berço da colonização alemã no sul -, para citar alguns exemplos que afligiam o observador nazista. Segundo sua percepção, o "problema" era o "alemão com hífen", isto é, o teuto-brasileiro,

63 Von COSSEL, H. H. Eine Reise durch das Deutschtum in Brasilien. In: Wir Deutsche in der Welt, editado pelo Verband Deutscher Vereine im Ausland. Berlin: Otto Stollberg, 1935. p. 49-62.

64 Com a lei Dellbrück de 1913, os descendentes de alemães nascidos do exterior também eram considerados cidadãos alemães, o "Auslandsdeutsche", portadores de dupla cidadania (sobre a definição de Auslandsdeutschtum, ver Rinke, op. cit., v. 1, p. 316-317).

65 Cossel, op. cit., p. 54. 
aquele que já não possuía mais a cidadania do reino alemão. ${ }^{66} \mathrm{E}$ este teria que ser reabsorvido pela "comunidade sanguínea", afirmando o anseio da "regermanização" dos nazistas. Mas Cossel não articula um projeto mais específico, pelo menos não nesse artigo. Faz somente sugestões mais gerais. Para que o Deutschtum fosse preservado, seria necessário criar um elo entre os alemães e fortalecer os aspectos econômicos e culturais. E, neste sentido, os veículos mais importantes para a realização dessa tarefa eram os fortalecimentos da escola e da igreja. ${ }^{67}$

Cossel queria garantir por esses meios que o imigrante alemão preservasse a identidade germânica, sem correr o risco de assimilar a cultura receptora. Essas projeções regermanizadoras, porém, não se realizaram diante do avanço nacionalista imposto por Getúlio Vargas. Na campanha de nacionalização do Estado Novo, a partir de 1937, o ponto de partida era "abrasileirar" os estrangeiros e seus descendentes em nome da formação de uma unidade nacional, de um espírito nacional. A propaganda nazista e o ideário de "regermanização", tal qual Cossel o veiculou, teriam sido os principais argumentos para justificar a intervenção nas colônias alemãs e forjar a "assimilação compulsória dos descendentes de imigrantes" para erradicar os "quistos étnicos", também por meio da força. ${ }^{68}$ Por fim, a entrada do Brasil na Segunda Guerra Mundial ao lado dos aliados provocaria uma enorme fissura na germanidade e na identidade teuto-brasileira. Mas, a essa altura, Cossel já estava retornando para a sua pátria.

\section{Considerações finais}

Os cinco autores aqui brevemente tratados são uma pequena amostra da variedade de tipos de viajantes e de viagens realizadas nessas primeiras décadas do século XX. Vallentin viaja ao Brasil com o Império colonial na cabeça. Seu texto pragmático dialoga com os interesses eco-

66 Segundo Cossel, em Curitiba viviam cerca de 25.000 "alemães" que formavam $25 \%$ da população total. Somente $10 \%$ destes alemães eram "alemães do reino". (Ibidem, p. 54).

67 Ibidem, p. 61.

68 Cf. SEYFERTH, Giralda. A colonização alemã no Brasil. In: FAUSTO, Boris. (Org.). Fazer a América - a imigração em massa para a América Latina. São Paulo: Edusp, 1999. p. 273-313. 
nômicos e geopolíticos, definindo uma tarefa bastante clara à imigração alemã no Brasil. Lembrando a definição de Mary Louise Pratt a respeito da função da literatura de viagem, é possível concordar que a narrativa de Vallentin cria um Brasil à mercê dos interesses dos centros hegemônicos, reiterando hierarquias, diferenças culturais e ideologias raciais. O Brasil, ou melhor, as suas regiões climaticamente amenas, tornam-se espaços ideais para a realização do projeto colonizador alemão vinculado a uma crença de superioridade racial.

Norbert Jacques representa o caso do escritor-viajante globe-trotter profissional, cujas obras têm uma enorme aceitação no mercado editorial alemão. O sucesso do escritor nasce com viagens aventureiras e seus textos leves, sem maior compromisso crítico. Edschmid, que não quer ser comparado ao globe-trotter, enquadra-se, porém, em semelhante perfil, embora tenha tido uma atuação anterior como literato. A sua prosa de viagem se configura num segundo momento de sua carreira, já não mais tão esplêndida, como uma forma de sobreviver e possivelmente se divertir com as viagens. E Zech, que forja uma viagem forçada, volta a escrever no contexto da errância. Nesses três casos, a experiência da viagem é fonte de inspiração para a realização do ofício como escritor, em que são produzidos textos ensaísticos com dimensões ficcionais. Pode-se aceitar a hipótese de que esses escritores estejam de fato mais afastados dos interesses neocolonialistas, deixando transparecer certa crítica ao imperialismo e à europeização do mundo. Por outro lado, como aduzido acima, a própria viagem exotista é cria do imperialismo europeu. Nesse aspecto, Zech parece ser o autor que mais reflete criticamente sobre o papel dos europeus no resto do mundo, provavelmente pela sua filiação política de outrora - a social-democracia - e o ativismo como pacifista, e talvez por estar na "diáspora", por mais que ela seja inventada pelo próprio protagonista.

No outro extremo, vimos o caso de Cossel, exemplo do viajante impulsionado por uma missão política e cuja abordagem se aproxima de Vallentin. Nesse caso, a narrativa se volta toda para um objetivo resultante de um olhar focado numa questão central, a germanidade no Brasil como continuidade da presença do "sangue alemão" mundo afora, porém, já num período em que a Alemanha não tinha mais colônias ou protetorados imperiais.

Todos esses autores, em sua necessidade de narrar, quer pelo gosto de viajar (capitalizado por interesses editoriais e financeiros), quer pela 
angústia de ser um fugitivo (por crime ou perseguição), quer pela missão política a ser cumprida, falam de um Brasil visto por "olhos pátrios". Aqui temos a imagem do Brasil "contramundo", antimaterialista e mais humano e consciente de seu papel no palco mundial, do Brasil-paraíso racial e repleto de belas mulheres negras, o Brasil da miséria e injustiça social, o Brasil germânico no qual reside uma parcela do futuro dos alemães e que precisa ser resgatado pelos laços de sangue. Certamente essas imagens são construídas em virtude das próprias inquietações dos viajantes e os motivos de sua viagem, que nos casos aqui apresentados caminham entre a produção literária de um mundo europeizado e o pragmatismo de interesses de dominação imperialista.

Recebido em agosto de 2012. Aprovado em abril de 2013. 